\title{
Assessing the Capacity of Pension Institutions to Promote Distributive Justice: A “Liberal” Conceptual Framework
}

\author{
Mark Hyde ${ }^{*}, 1$, John Dixon ${ }^{2}$ and Glenn Drover ${ }^{3}$ \\ ${ }^{1}$ School of Law and Social Science, University of Plymouth, United Kingdom \\ ${ }^{2}$ Department of Public Administration, Kazakhstan Institute of Management, Economics and Strategic Research, \\ Kazakhstan \\ ${ }^{3}$ School of Social Work, Dalhousie University, Canada
}

\begin{abstract}
Much of the literature regarding distributive justice and pensions has focussed disproportionately on the material preconditions for social solidarity, particularly statutory measures that would narrow the scope of differentials in the distribution of income and wealth. While we are sympathetic towards this emphasis, we contend that justice is comprised of a range of distinctive normative principles. Drawing upon an appraisal of the principal arguments of two highly influential public philosophies, this article develops a "liberal" conceptual framework which specifies the normative foundations of appropriate pension scheme design. The core principles of justice are need, which legitimates the social minimum that is necessary to sustain an adequate standard of living for the least advantaged; desert, which provides a justification for allocating income in accordance with differentials in work participation prior to retirement; and equality, which provides a normative rationale for universal citizenship entitlements. Their corresponding programme design features may be used to assess, empirically, the degree to which the design of pension institutions is consistent with the requirements of distributive justice.
\end{abstract}

\section{INTRODUCTION}

To the extent that it has acknowledged the importance of justice, much of the scholarly literature in the pensions field has focussed on the material preconditions for social solidarity, particularly "decommodification", or the allocation of income in accordance with egalitarian normative principles. It asserts that vast disparities in income and wealth are destructive of the mutual obligations that give people a sense of rootedness, highlighting the importance of statutory measures to circumscribe the scope of social inequalities. Esping-Andersen [1] maintains that universal social rights constitute a power resource that augments the capacity of the working class to initiate and sustain collective action. Its capacity to challenge the power and authority of corporate elites is, in contrast, diminished under "liberal" welfare states, because employees in de-regulated markets are "inherently atomised and stratified-compelled to compete, insecure, and dependent on forces and decisions beyond their control" (p. 16). Similarly, Leonard [2] is clear that the collective action that decommodification makes possible confers considerable psychological benefits on individual members of the working class, empowering them to move beyond the "cult of individualism" that suffuses inter-personal relations under capitalism. Liberal welfare states require workers to "remain fragmented from each other" and encourage "competition and envy" (p. 212). In short, the justness of pension institutions should be appraised in terms of the degree to which their design has embraced decommodification.

*Address correspondence to this author at the School of Law and Social Science, University of Plymouth, Plymouth, PL4 8AA, United Kingdom; Tel: +44 (0)1752 233230; E-mail: mhyde@ plymouth.ac.uk
This analysis is inherently flawed, and for at least two reasons. First, although solidarity could be regarded as an important political ideal, it is not the only relevant concern of justice. Second and reflecting this omission, it embraces a one dimensional view of the normative foundations of liberal retirement systems: "liberal" is equated with "neoliberal", which means that liberal retirement systems are regarded as hostile to egalitarian concerns. But in reality, contemporary liberalism is characterised by a rich diversity of perspectives that may encompass the principle of equality, as well as a concern with the particular circumstances of the least advantaged.

The central aim of this article is to develop a distinctive liberal conceptual framework that may be used, empirically, to assess the capacity of pension institutions to promote intragenerational justice, or justice among retirees. In approaching this task, we have drawn upon several of the insights of two disciplinary approaches to the analysis of justice. Political philosophy is concerned principally with the legitimacy of social institutions, particularly their appropriate normative foundations. According to one prominent contemporary political philosopher, David Miller [3], it "tells us what we ought to think about justice" (p. 42), by engaging with and adjudicating between contending conceptions of normative principles, in order to determine those that should be deployed to justify institutional arrangements. Political philosophy is not typically concerned with developing programmes of reform that can instantiate normative principles, or with their sustainability, and has therefore been vulnerable to the criticism that it offers little practical guidance to those who are charged with the responsibility for designing social institutions [4]. In contrast, social science is concerned principally with the 
dynamics of justice, particularly the design, societal impact and sustainability of income transfer programmes. This applied orientation is of considerable relevance to those with the responsibility for designing social institutions, but is vulnerable to the criticism that it may lack a critical and coherent normative rationale for preferred institutional arrangements. For Millar [3], this reflects the tendency of social scientists to "bracket off the question of what justice really is, and see themselves as investigating justice beliefs and justice behaviour without the theoretical presuppositions" (p. 43). We believe that an adequate account of justice must acknowledge the strengths of both approaches. If it is to distinguish dynamics of policy that are consistent with justice from those that are not, social science requires an appropriate normative theory. But if it is to give rise to principles that can reliably and sustainably be instantiated by reformers, political philosophy requires a concrete understanding of the dynamics of justice.

Drawing upon insights from these distinctive traditions, our analysis is pursued in two ways. First, we identify a set of principles that should inform a liberal assessment of the capacity of pension institutions to promote distributive justice. This is achieved by reflecting on several of the principal themes and arguments of two liberal public philosophies, libertarianism [4,5] and liberal egalitarianism $[6,7]$. Put schematically, the core principles of justice are need, which legitimates the social minimum that is necessary to sustain an adequate standard of living for the least advantaged; desert, which provides a justification for allocating income in accordance with differentials in work participation prior to retirement; and equality, which provides a normative rationale for universal citizenship entitlements. Second, we specify an indicative set of social security programme design features that correspond to each of the principles, providing a foundation for empirical research regarding the degree to which the design of pension institutions is consistent with the requirements of distributive justice. This is achieved by teasing out the implications of the three justice principles through a discussion of the social science literature regarding the dynamics of retirement systems.

\section{JUSTICE AND PENSION INSTITUTIONS}

Defined broadly, the core intuition of justice is the realisation of a fair distribution of entitlements and obligations, where all individuals receive their due, however this is defined [6]. "Distributive" justice addresses the normative principles that are consistent with the attainment of a fair distribution of "material" resources, particularly income [8]. We develop this concern with specific reference to retirement provision. As defined by Möllering [9], pension institutions are the "range of socially constructed, routine reproduced (ceteris paribus) programmes or rule systems that reflect and are designed to reinforce" particular retirement outcomes (p. 16). Our core concern is the impact of pension scheme design on the allocation and distribution of retirement income.

As we have suggested, liberal justice manifests in two broadly distinctive ways. To the extent that they regard justice as an important concern, libertarians are committed to the principle of negative freedom, which requires a minimal state to protect individuals against coercion. Natural rights libertarians [5] reject the assertion that justice should be appraised in terms of end-states such as an egalitarian distribution of resources. The legitimate scope of public authority encompasses the maintenance of a legal and coercive apparatus that reliably convicts and punishes those whose actions violate inalienable individual rights. But consequentialist libertarians [4] appraise social institutions in terms of distributive outcomes, since the propriety of any system of justice would be questionable if it did not routinely optimise welfare. For them, individual freedom is important precisely because it generates and diffuses the benefits of economic prosperity. Libertarians generally endorse a framework of retirement provision that emphasises individual over collective responsibility.

In contrast, liberal egalitarians maintain that free markets routinely allocate resources in ways that may undermine individual freedom. An egalitarian distribution of resources is necessary to ensure that all individuals are given the means to pursue their conception of the good life. Prioritarians regard equality as a means to an end, such as improvements in the absolute position of the poorest in society. Thus for Rawls [12], inequalities in the distribution of resources are acceptable to the extent that they result in income transfers that augment the circumstances of the least advantaged. But egalitarianism "strictly speaking" [6] regards substantive equality as an end in its own right, for all individuals require the resources that are necessary to ensure that their choices and actions reflect their sovereign preferences. Liberal egalitarians generally emphasise a framework of retirement provision which includes redistributive statutory income transfers.

In a variety of ways, then, individual freedom is the paramount concern of liberal justice. Following Miller's seminal contribution $[3,10]$, our initial specification of justice principles starts from the concrete societal relationships in which agents are situated, rather than hypothetical abstractions.

\section{NEED}

Miller's first mode of societal relationship is "solidaristic community", giving rise to the principle of "need" [3]. The moral force of this element of distributive justice rests on the claim that all communities embody a sense of the "standards that an adequate human life must meet". As a matter of justice, "each member is expected to contribute to relieving the needs of others in proportion to ability" (p. 27), and in proportion to the impaired capacities of the disadvantaged. Beneath the rhetoric, the two public philosophies that have informed our analysis seem to concur that extremes of disadvantage are morally unacceptable, suggesting that social institutions should be appraised in terms of the extent that their design addresses the circumstances of the least advantaged satisfactorily.

\section{Normative Foundations}

In one sense, libertarianism is hostile to the moral imperative that is embedded in the concept of need. The natural rights rejection of end-state principles necessarily means that any moral value that requires resource distribution to take a particular shape is irrelevant to an 
appraisal of the justness of social institutions. As Olsaretti's influential analysis of this approach [8] observes, "there is only a correct or fair procedure [the protection of negative rights] such that the outcome is likewise correct fair or correct, whatever it is" (p. 87). Consequentialist libertarians have similarly dismissed need as an arbitrary subset of individual preferences that is cynically deployed by public "servants" to justify extensive public expenditure commitments in pursuit of electoral advantage [4]. While they reject the concept of need, however, libertarians acknowledge the possibility of extremes of disadvantage that may impact adversely on individual welfare, and which should therefore be regarded as morally unacceptable. They have addressed this concern in terms of the "congruency thesis", which maintains that the institutions that are consistent with negative liberty will respond satisfactorily to the problem of social disadvantage [5]. It is asserted that the voluntary approach to insurance against economic misfortune provides individuals with both the opportunity and incentive to optimise their retirement planning, diminishing their risk of income deprivation as pensioners. Mitchell and Utkus [11] suggest that libertarianism has embraced the "rational actor model", which assumes that individuals "are rational planners of their consumption and savings over their lifetimes". During middle age, they "become net savers and purchasers of financial assets", stockpiling resources for "the final retired phase of life" (pp. 4-5).

Furthermore, it is maintained that voluntary exchange fosters philanthropic effort, augmenting the material circumstances of the least advantaged. But the argument that the intensity of economic disadvantage can ground a corresponding right to resources is misleading, and for two reasons. First, the positive obligations that are embedded in redistributive income transfers are acceptable to the extent that they are self-imposed, reflecting the priority that is attached to self-ownership. Although it is morally appropriate for individuals to relieve suffering and distress when they encounter it, their can be no legitimate legal obligation to do so [5]. Second, the intensity of economic disadvantage is not the principal moral concern that should inform the administration of assistance. Of paramount importance is the degree to which the least advantaged can be held responsible for their adverse circumstances. In particular, philanthropic effort should be targeted at the "deserving"-those whose misfortune arises because of circumstances that are beyond their control and, in cases where individuals can be regarded as responsible, those who demonstrate a commitment to take appropriate action in the future. This means that assistance should be withheld from the "undeserving" irrespective of concerns regarding the intensity of their disadvantage [4].

Although we welcome any concern to augment the specific circumstances of the least advantaged, it is difficult to share this sanguine appraisal of the efficacy of voluntary insurance. Following Mitchell and Utkus [11], we acknowledge that agents generally accept the importance of retirement planning, but it is clear that "they struggle to take action, and when they do act", they "over-value the present", and "under-save", reflecting "self-control problems" (p. 6). The capacity of philanthropic effort to accommodate the needs of the least advantaged is similarly questionable, because there is no compelling evidence to suggest that the values of the enterprise culture, including independence, competition and acquisitiveness, will intensify private altruism. Moreover, the discretionary nature of philanthropic effort means that its administration is likely to be inequitable, which is of course incompatible with the universal importance of needs satisfaction. For these reasons, a reliance on voluntary exchange is likely to result in suboptimal retirement outcomes, including a higher prevalence of unmet need.

The moral impetus of need as a principle of distributive justice has figured prominently in liberal egalitarian political philosophy, as reflected in Rawls' analysis of "primary goods" [12], particularly his argument that a denial of access to the resources that they encompass will undermine dignity and self-respect without which "nothing will seem worth doing" (p. 538). Yet according to Barry's appraisal [13], Rawls has very little to say about the specific nature of the relationship between primary goods and individual welfare, nor is there any attempt to "get behind his general redistributive rules to determine the typical needs that are visible in modern societies" (p. 88). Arguably, this imposes an unacceptable degree of ignorance on those who are required to endorse distributive justice, on whose decision making much depends. In the real world, the failure to articulate a morally compelling concept of need may undermine the willingness of taxpayers to finance the redistributive income transfers upon which the least advantaged depend.

Millar [3] has responded to this challenge by specifying the distinctive forms of need that may ground claims regarding the societal distribution of resources. "Instrumental" needs are concerned only with the preconditions for the satisfaction of subjective preferences, which means that they cannot carry disproportionate moral weight in the determination of resource allocation. "Intrinsic" needs, in contrast, may be regarded as "objective" in that they refer to the minimally necessary requirements for the avoidance of harm, which impairs human capacities. They include "biological" needs, which are defined principally in terms of health status, and "social" needs, which focus on the preconditions of participation in the roles and expectations that are widely endorsed by particular societies. The moral force of need as a distributive imperative is thrown into sharp relief when the consequences of unmet need are considered. When agents are unable to "enter public space without shame", argues Miller [3], "a whole range of activities from work to recreation to political participation will be inaccessible, or accessible only on pain of great discomfort" (p. 210).

By extension, liberal egalitarians acknowledge the importance of addressing variations in the impaired capacities that give rise to need. The recent work of Dworkin [6] has developed a normative framework for justifying the elimination of involuntary disadvantages, or those that reflect unchosen external resource and internal native endowments. His conception of justice as outcomes that reflect individual choice rather than circumstance requires statutory income transfer programmes to compensate individuals according to the degree of their involuntary disadvantage. However, this approach is vulnerable to the objection that it ignores the needs of those whose misfortune arises because of choices for which they were responsible. 
Van Parijs [7] asserts that a genuine concern with the autonomy of all requires the public authority to leximin the distribution of opportunities, by ensuring that the least advantaged are no more disadvantaged than they would be under any feasible alternative arrangement. Once their opportunities have been addressed, the next disadvantaged on the scale must be no more disadvantaged than they would be under the alternative, and so on. While much of this can be taken care of by a universal basic income, the particularly adverse circumstances of those with impaired internal capacities require additional targeted assistance. Liberal egalitarian justice thus requires statutory income transfer programmes that are sufficiently flexible to address variations in the intensity of need.

Even when the radically different normative premises of the two public philosophies that have informed our analysis are taken into account, then, the moral force of public action to address the particular circumstances of the least advantaged is clear.

\section{Programme Design}

How does this translate into requirements for the design of pension institutions? Because its central aim is to facilitate basic income security, the first pillar retirement income safety-net is widely regarded as the appropriate administrative locus of needs-focussed social security transfers. Regardless of differences in design, the first pillar is intended to supplant the market as an institutional framework for resource allocation, guaranteeing an income floor below which no one should fall. Our analysis highlights the importance of two issues: access, which concerns the conditions under which individuals may be eligible for transfers; and benefit adequacy, which refers to the capacity of transfers to accommodate needs. Both may usefully be illustrated with reference to the debate regarding the efficacy of two broad strategies for the first pillar retirement income safety-net.

The first is "selectivity", which is premised on the argument that needs are most effectively addressed by distributing resources to the least advantaged through targeted transfers $[14,15]$. The most prevalent variant of this approach is social assistance, an income transfer programme that is financed from general taxation, paying benefits to those who first demonstrate limited economic means. When considered in terms of its capacity to address needs, the advantages that are claimed for social assistance are twofold: flexibility-because eligibility is determined only in accordance with need (however defined) rather than prior economic behaviour such as labour force participation or savings, benefits can be tailored to individual circumstances; and efficiency-social assistance programmes make the best use of scarce resources by targeting transfers on those who need them the most. In principle, the restriction of access to the least advantaged increases the probability that transfers will be sufficient to address needs.

But social assistance is characterised by several fundamental flaws, detracting from its effectiveness as a needs-focussed social security strategy. Perhaps the most prominent is stigma, which Reisman [14] defines as a "loss of self-respect and personal dignity, a sense of guilt, of shame, of personal fault and failure" (p. 41). Alcock [15] regards stigma as the inevitable consequence of meanstesting, "since if benefits are targeted on the least advantaged, "there will always be the fear that those who do not need them are somehow managing to get them" (p. 31). This gives rise to a second salient problem, non-take-up, because "ignorance, fear and, in some cases, pride mean that many who are entitled to benefits do not claim them" (p. 31). Moreover, in targeting transfers on the least advantaged, social assistance typically fails to command popular support, suggesting that benefits are likely to be parsimonious and therefore, insufficient to lift people out of poverty.

The second broad social security strategy is "universality", which aims to guarantee basic income security by distributing resources to all retirees [14, 15]. According to Hills [16], this could be achieved by extending access to existing first pillar social insurance retirement schemes. Under selective social insurance (SSI), access is restricted to the "economically active" and increasingly, those who are disproportionately responsible for domestic labour. This means that retirees with insufficient contributions have little choice but to rely on social assistance, which increases their risk of income deprivation. The proposal for universal social insurance (USI) addresses this by extending access to all retirees, regardless of their prior contributions; by endorsing transfers that are sufficient to prevent income deprivation; and by retaining the insurance principle, to give the appearance that benefits have been earned. USI is redistributive to the extent that the benefits of those without a sufficient contribution history are financed from the contributions of others.

While these design attributes might suggest that USI is preferable to the means tested alternative of social assistance, however, it could be regarded as morally ambivalent. Goodin [17] observes how, on the one hand, it embeds eligibility in the moral repertoire of desert, because individual contributions serve "politically, morally and psychologically...to vest the person's subsequent entitlements to benefits" (p. 536); but on the other, it gives entitlements to all retirees, regardless of differentials in contributions or involvement in economic activity, suggesting that citizenship is regarded as the relevant principle of resource allocation. Alcock [15] is critical of this approach because if there are no contribution conditions, "then in what sense are benefits claimed as a right because they have been paid for? And in what sense are...contributions any more than part of general taxation for social security expenditure?" (p. 38). In reality, it isn't clear that this approach would be any more an insurance based scheme than an income transfer programme that is financed from general taxation.

This moral ambivalence is arguably addressed by a second variant of universality, the universal citizens pension (UCP) [18, 19]. The normative justification for a UCP is derived from arguments regarding the social rights of citizenship, which means that access would be extended to all who meet defined age and residence conditions. When considered in terms of its capacity to address need, the advantages of this approach are similar to those of USI: automatic qualification for transfers eliminates the requirement to advance a claim and by extension, the possibility of non-take-up; and universality augments 
political support for the programme, reducing the likelihood that benefits will be parsimonious [20].

It could of course be argued that the absence of eligibility conditions condones "free riding", enabling the genuinely inactive to exploit the labour of those who have participated in productive activity [21]. At the very least, eligibility for benefits from a citizens pension should be premised on a minimum work requirement, which could manifest as "strict reciprocity"-the requirement that benefit entitlements should reflect contributions; or "baseline reciprocity"- the requirement for a "decent minimum" of lifetime productive activity. While these proposals may have intuitive appeal, work testing is clearly incompatible with the moral impetus of needs satisfaction. Its presumption that agents can and should be held responsible for their failure to demonstrate sufficient involvement in productive activity prior to retirement is at variance with the reality of discrimination and disadvantage in contemporary labour markets [7]. Crucially, the elimination of those who fail to satisfy the requirements that are embedded in the reciprocity threshold would convert the UCP to a SSI programme, where retirement income is allocated in accordance with desert. Those who fail to qualify for transfers under this arrangement would be forced to rely on social assistance, which is characterised by uneven take-up and insufficient benefit entitlements. Ultimately, the adequacy of the first pillar retirement income safety-net should be judged in terms of its capacity unmet need, suggesting that reciprocity is an irrelevant concern.

The challenges that are inherent in the design of a universal tax-financed first pillar safety-net give rise to several questions (Table 1). First, what is the appropriate form of benefits? This arises in part because several of those who endorse the social security model from which the UCP is derived insist that transfers should be distributed as a oneoff grant. Van Parijs [7] rejects this argument on the grounds that it might result in the creation of a "crowd of elderly destitutes who are paying a heavy price for squandering their one-off endowments" (p. 31). Periodic payments would ensure that purchasing power is spread evenly across the span of a persons' retirement.

Second, what are the appropriate eligibility conditions for transfers? This is relevant to our concerns in at least two ways. The UCP model is informed by the principle of citizenship, suggesting that eligibility should be determined only in accordance with age and residence. While sustainability is an important concern (see below), these requirements should not be so stringent that they prevent older citizens from accessing the programme. This emphasis on citizenship means of course that the UCP model generally endorses uniform or flat-rate benefits, yet need manifests with varying degrees of intensity. This suggests that universal entitlements should be supplemented by variable transfers to accommodate individual circumstances, with eligibility tied in some way to the intensity of need.

Third, what is the appropriate income threshold upon which universal transfers should be based? The case for a first pillar safety-net was originally developed in terms of arguments regarding the income that is necessary to prevent subsistence poverty, but this fails to acknowledge the importance of individual capacities to function in socially recognised ways. However, policy makers are confronted by an uneasy tension between access and benefit adequacy, for the inevitable corollary of universality is fewer resources to augment individual entitlements. One solution to this dilemma is to insist that universal entitlements should be at least sufficient to permit subsistence, and as generous as is sustainable above this level. Naturally, the value of entitlements should be preserved across time through appropriate benefit indexation.

In principle, then, liberal justice requires a universal taxfinanced first pillar retirement income safety-net which confers entitlements that are sufficient to address unmet need. However, any proposal for a substantial social security reform on this scale is likely to raise legitimate concerns regarding sustainability. The fact that a social institution is "well-ordered" in the sense that its design corresponds to the requirements of a normative principle such as justice does not mean that it has the capacity to endure over the longterm. Following Rawls [12], we might regard social institutions as sustainable if their design generates forces that support their endurance. As we have noted, a UCP is likely to generate an enormous reservoir of electoral support, augmenting its political sustainability. But any approach to social security that confers unconditional entitlements is likely to generate enormous economic costs, raising questions about its fiscal sustainability, especially in low income and "developing" countries. Putting the heated debate on this issue to one side, it is clear that the evidence regarding the fiscal sustainability of universal tax-financed universal income transfers is inconclusive.

The sustainability of the UCP model in a western context is highlighted by the Dutch first pillar pension arrangement which has conferred universal entitlements to a retirement income for more than half a century. The full citizens pension is set at the level of a state defined social minimum, guaranteeing a retirement income floor that is sufficient to prevent poverty. However, this stability is achieved in part

Table 1. The Design Requirements of the Needs-Focussed First Pillar Retirement Income Safety-Net

\begin{tabular}{|c|c|}
\hline Design Priorities & Design Features that Augment Justice \\
\hline \hline Access & Universal transfers, subject to age and minimum residence requirements \\
\hline \multirow{3}{*}{ Benefit adequacy } & Periodic payments \\
\cline { 2 - 2 } & Transfers as high as is sustainable above the subsistence level \\
\cline { 2 - 2 } & Appropriate benefit indexation \\
\cline { 2 - 2 } & \\
\cline { 2 - 2 } &
\end{tabular}


through stringent residence requirements, which mean that the incomes of partial residents with no other pension entitlements will fall short of the state-defined poverty threshold, resulting in dependence on social assistance, and exposure to the risk of non-take-up. Nevertheless, the Netherlands has one of the lowest rates of retiree poverty in western Europe [22], an achievement that may be attributed in part to its sustainable UCP arrangement.

The sustainability of the UCP model in the context of developing economies could be highlighted by its adoption and endurance in a handful of countries-Mauritius, Bolivia, Namibia, Botswana, Nepal, Samoa-and Mexico City. It should be acknowledged, however, that the achieved coverage of existing UCP arrangements in low income countries is uneven, ranging from 77 percent in Nepal to a recorded 105 percent in Bolivia [23]. Above all, the evidence suggests that their capacity to address unmet need satisfactorily is variable. According to Willmore's recent study [23], none of these first pillar pension arrangements could be described as "generous", but entitlements in Mauritius and Namibia-currently 16 percent of per capita GDP - are sufficient "to ensure that few experience extreme poverty or deprivation in old age". In contrast, entitlements under the first pillar in Nepal and Mexico Cityapproximately 10 percent of per capita GDP_- "are clearly inadequate" (p. 11).

Ultimately, Willmore's analysis is optimistic about the possibility of designing and instituting UCP arrangements that can address unmet need satisfactorily while being fiscally sustainable, even in low-income countries. In particular, he maintains that a UCP arrangement could be sustained by redistributing the considerable public resources that currently subsidise second pillar retirement schemes to transfers for the least advantaged. Alternatively, the fiscal sustainability of an adequate needs-focussed UCP arrangement could be augmented by introducing a degree of progressivity in the tax treatment of retirement income (a form of ex post means testing), so that each citizen "is entitled to a flat pension upon reaching the age of eligibility, but she is also required to return part or all of it out of other income she receives during the year" (p. 29). The advantage of this approach is that the taxation of retirement income is voluntary, since it can be legally avoided by choosing not to take up UCP entitlements. Nevertheless, if the UCP model ultimately proved to be fiscally unsustainable in any particular national jurisdiction, it could be worth considering more acceptable forms of selectivity that proactively recruit the least advantaged, such as a negative income tax, or the World Bank's proposal for a minimum pension guarantee [24]. While these alternatives do not eliminate the problem of non-take-up or the possibility of parsimonious benefit entitlements, they are preferable to social assistance programmes that give the responsibility for claiming entitlements to retirees. However, the propriety of any selective approach must also be considered against the requirements of our third principle of justice, citizenship (see below).

\section{DESERT}

Miller's second mode of societal relationship is "instrumental", giving rise to the principle of "desert" [3].
The moral force of this element of distributive justice rests on the claim that each individual is "a free agent with a set of skills and talents that he [sic] deploys to advance his goals. Justice is done when he receives back by way of reward an equivalent to the contribution he makes" (p. 28). Olsaretti [25] conceptualises desert as involving a three place relationship between an agent (the deserving subject), the grounds upon which the agent may be regarded as deserving (the desert basis), and the treatment that is deserved (the deserved good). Although there are many potential grounds for defining and acknowledging desert, our focus on the distribution of retirement income means that we are necessarily concerned with "economic" desert which, for the vast majority, concerns the degree of correspondence between the allocation of "earnings" and differentials regarding work participation, or "productive achievement".

Miller [3] maintains that desert necessarily entails an "appraisal" of the deserving subject, which means that the relevant standards of individual performance regarding productive achievement could be established in terms of "what is positively...valued by the surrounding community" (p. 141), as reflected in consumer demand. In principle, the aggregation of individual preferences through the price mechanism has the potential to provide reliable estimates of the "value to society" of the individual's engagement with work. Provided that "markets remain competitive, and provided that enterprise managers make a conscientious effort to assess the respective contributions of the people they employ", there is no reason why "rewards should not correspond to desert in the form of productive achievement" (p. 193). The alternative is to rely on the political process to determine the value of individual productive achievements, as reflected in the remuneration of those who are responsible for supplying public services. For Miller [3], this is appropriate to the extent that the services in question may be regarded as a merit good that is necessary to satisfy the requirements of a prior principle of justice, such as need, or as a public good which would be under-supplied in the market. Still, whenever work involves the production of a public service, there is likely to be some indeterminacy in estimating the value of a person's contribution.

These concerns suggest that pension institutions may be regarded as just to the extent that the income they are responsible for allocating has been "earned" by productive achievement.

\section{Normative Foundations}

Libertarianism is generally ambivalent regarding the importance that should be assigned to desert. The natural rights libertarian rejection of end-state principles could suggest that desert is irrelevant to an appraisal of the justness of pension institutions [5]. In responding to the assertion that resource allocation in the market is morally arbitrary, however, natural rights libertarians insist that the transactions it encompasses are typically desert-focussed, for individuals have expectations about their due based on the effort they contribute to production. Indeed, the protection of agents from coercion enables them to develop the capacities that do justice to opportunities that are embedded in their entitlements. Consequentialist libertarian arguments, including those deployed by Schmidtz [26], regard desert as 
being integral to the incentives that drive free enterprise and economic prosperity, because the purpose of the market economy is to "give people the reason and the opportunity to race for the finish line" (p. 85). And as we have noted, arguments regarding deservingness are central to libertarian analyses of the administration of economic assistance for the least advantaged [4].

One of the principal strengths of libertarianism is its recognition that a defensible principle of desert must be responsibility-sensitive: agents are desert evaluable precisely because they are causally responsible for their decisions and actions. Perhaps the central problem with this argument, however, is its endorsement of voluntary exchange and by extension, the centrality of negative rights as a constraint on the legitimate scope of public action. Desert provides a moral focus for appraising individuals to the extent that it is appropriate to give respect to those who live well by acting in accordance with their potential, which means that voluntary action is not beyond criticism. But it cannot be a matter for public concern since this would violate the principle of self-ownership, which includes the right to act in a morally arbitrary way if this is deemed to be appropriate by agents. We believe that this anomaly may only be addressed satisfactorily by relying less on desert as a principle of resource allocation, which would mean that it could not be invoked to justify market transfers, or by endorsing appropriate public action to ensure that retiree income inequalities are grounded in appropriate desert bases.

There is considerable disagreement between liberal egalitarians on the importance of economic desert as a principle by which the justness of social institutions should be appraised. On one side stand those who have embraced the "non-responsibility thesis". Rawls [12] concurs that a defensible principle of desert must be responsibilitysensitive, but questions the capacity of agents to exercise such responsibility, because their choices are shaped by contingencies that lie outside of their control. If agents are not sufficiently responsible for their actions, and thus have no legitimate moral claim to the resources that they are able to accumulate, then any attempt to justify income inequalities in terms of the desert principle would give some unfair advantages over others.

This powerful challenge to the propriety of desert as a principle of distributive justice could be addressed in two ways. It could be argued that desert does not require responsibility. Regardless of the degree to which agents are appropriately responsible for their actions, notions of desert are integral to the incentives that drive productive effort, which ultimately generates the resources upon which the difference principle depends [26]. However, this fails to acknowledge McLeod's argument regarding appropriate distinction between merit and desert [27]. The former, which is "based on the possession of any quality that is an appropriate basis for treatment" (p. 12), does not require the individual to be appropriately responsible for the attributes that result in differential rewards. Desert claims, in contrast, are claims regarding the moral worth of agents, and moral claims require responsibility.

Alternatively, Olsaretti [8] maintains that desert is a defensible principle of justice where three particular conditions are satisfied: voluntariness of choice — agents may be regarded as sufficiently responsible for the development and deployment of their desert-evaluable productive capacities when their choices are "neither tainted by force nor the result of factors that are wholly outside of" their control (p. 166); fair opportunity - a defensible principle of desert "that can justify differential rewards recognises that individuals should have fair opportunity to deserve more or less than others" (p. 165); and equivalent treatment-desert should be regarded as "comparative", requiring "equality in the treatment of all members of a given [comparison] class" (p. 18). This approach to desert requires policies to minimise differential brute luck, including a robust social minimum for those of working age, to facilitate voluntariness of choice regarding the development of appropriate productive capacities; anti-discrimination legislation to ensure a fair distribution of opportunities to deploy productive capacities; and fiscal policies to reduce the incidence of unearned income and wealth. Still, Miller [10] acknowledges that it might be overly optimistic to expect that luck could be eliminated entirely from economic transactions. Rather, these policies seek to protect "people from the worst kinds of bad luck, and dampen down the cumulative effects of good luck" (p. 17).

In sum, the desert principle requires remuneration to track productive achievement, highlighting the importance of public action to ensure that justice claims are grounded in appropriate desert bases.

\section{Programme Design}

It could be maintained that economic desert is irrelevant to retirement, since it requires only that agents are appropriately remunerated for their productive achievements. Nevertheless, the desert principle has figured prominently as a justification for occupational pensions, which were originally presented by their architects "as a reward for services rendered to society by its members over their lifetimes". Freeden [28] believes that their introduction "signalled that some rights could be earned, and by implication, could fail to be earned" (p. 33). Indeed, Kangas [29] maintains that economic desert is the unifying theme of diverse occupational pension arrangements, since "all entitlements and rewards related to previous income and employment or work history are expressions of the "to everybody according to his/her merits' thinking" (p. 2). To the extent that retirement schemes have been justified according to this moral repertoire, their design should be consistent with the requirements of the desert principle.

Fundamentally, the maxim that income should be earned by productive achievement must require the deferral of earnings through individual saving, as expressed by the contributory principle, which is characteristic of second pillar (henceforth "supplementary") retirement schemes. This is expressed succinctly by Goodin's observation [17] that the "larger the premiums you have paid (or the greater contributions you have made, more generally), the more you are entitled to receive". Underlying the "argument that benefits should be earnings-related because contributions have been is the deeper claim that people should get all that they pay for and only what they pay for" (p. 536). Naturally, this emphasis on the deferral of earnings should encompass the circumstances of all who are engaged in productive 
activity, including those who are involved in unpaid domestic labour. Justice is served to the extent that the income that pension institutions are responsible for distributing has been earned by prior productive achievement. This means that the distribution of retirement income may be regarded as just only to the extent that the market distribution from which it is derived is consistent with the requirements of the desert principle. Our analysis highlights the centrality of three issues that are specific to the design of pension institutions.

The first issue is security (Table 2), which is defined generally by Vail [30] as a "condition of stability or permanency, where an individual has reliable expectations of continuity in their surroundings and relationships" (p. 7). It has been asserted vociferously that only the state has the capacity to guarantee income security for its citizens, including those who are affiliated to supplementary retirement schemes. In particular, social insurance schemes are regarded as offering the highest degree of retirement income security, reflecting two of their salient characteristics: pay-as-you-go (PAYG) financing, which eliminates investment risk; and state sponsorship, which is underpinned by the fiscal capacity to accommodate all future benefit liabilities, or so we are told [31].

Beneath the rhetoric, however, several features of PAYG financed supplementary retirement schemes may be incompatible with the security of legitimate earnings. First, they generally fail to regard retirement assets legally as property. Property rights are typically conferred through retirement-income-protection by a "contractual promise of benefits". The argument that social insurance schemes should confer such rights has been explicitly rejected by several of their advocates, including the United States Supreme Court [32], because "to engraft upon the Social Security system a concept of 'accrued property rights' would deprive it of the flexibility and boldness in adjustment to ever-changing circumstances which it demands" (p. 73). Following Schmidtz [33], we believe that desert and property rights are inextricably linked, for a society cannot work without a "rule of law system that secures people's earnings and savings, thereby enabling people to plan their lives" (p. 70). At the very least, the security of retirement income requires a legal framework of enforcement which regards property rights as inalienable.

Second, the administration of PAYG financed retirement schemes is characterised by a considerable degree of complexity, which means that it is difficult to determine the specific relationship between contributions and benefit entitlements. Although such schemes are widely regarded as "earnings-related", the entitlements that they are responsible for distributing are shaped by contingent factors that have little if anything to do with the allocation of legitimate earnings, including political and demographic risk. Not surprisingly, political decisions regarding the determination of benefit "entitlements" may be morally arbitrary when appraised in terms of the desert principle. Yet symbolically, the desert principle requires a visible relationship between appropriate desert bases and the differential allocation of rewards, which is easier to achieve in a system that is characterised by a high degree of epistemic accessibility. At the very least, this gives rise to the need for rigorous disclosure requirements regarding the concerns that influence the determination of retirement benefits.

One of the principal advantages of funded retirement schemes, in contrast, is that they do generally confer property rights regarding accumulated retirement assets. The greater security that is apparently offered by fully funded defined benefit (DB) schemes reflects two of their salient design attributes: income guarantees and the earnings-related principle. Conversely, the benefit entitlements that are derived from fully funded defined contribution (DC) retirement schemes depend largely on fluctuations in investment income during the accumulation phase, and thus cannot be known until the affiliated individual reaches retirement. According to Ginn [18], investment risk may be compounded by excessive administration charges, which siphon resources away from the affiliated individual's retirement assets, and "falling annuity rates, as insurers adjust to increasing longevity" (p. 9). The salient characteristics of the design and performance of DC schemes increase the probability that the allocation of the retirement income that they are responsible for distributing will be morally arbitrary, as evidenced by considerable variation in the benefit entitlements of those with similar contribution profiles [20].

Such outcomes are intuitively incompatible with economic desert as we have defined it, which requires similar contributions to be treated in an equivalent way, suggesting that the DB principle should be regarded as an integral element of a just supplementary pension arrangement. In endorsing this approach, we should acknowledge those contingencies which have circumscribed the capacity of DB schemes to deliver the substance of their promises, including growing benefit liabilities, reflecting increased longevity; insufficient assets, reflecting scheme mismanagement (as evidenced by inappropriate actuarial projections and contribution requirements); diminished rates of return from financial markets; and, in some cases, malfeasant administration. These contingent factors and their adverse consequences highlight the importance of measures to augment scheme solvency.

The second issue is the degree of inclusiveness (Table 2), referring specifically to the proportion of future retirees who are permitted to participate in the supplementary pension arrangement. The notion of "fair opportunity" that is embedded in the desert principle means that the circumstances of all with appropriate desert bases should be encompassed by relevant systems of resource allocation, including those that are responsible for distributing retirement income. A large number of existing supplementary retirement schemes, however, exclude from coverage one or more of two particular groups of those who are engaged in productive activity.

The first is those who, because they are involved in unpaid domestic labour, are deemed by the state to be "economically inactive", reflecting the salience of a work ethic that is centred on formal employment [1]. Research suggests that the failure of supplementary pension arrangements to include those whose productive achievements are realised through domestic labour has impacted disproportionately on women, reducing their capacity to save, and intensifying the risk of poverty during retirement [18]. For 
Table 2. The Design Requirements of the Desert-Focussed Second Pillar Pension Arrangement

\begin{tabular}{|c|c|}
\hline Design Priorities & Design Features that Augment Justice \\
\hline \multicolumn{2}{|r|}{ Security } \\
\hline General & Appropriate benefit indexation \\
\hline Property rights & Immediate vesting for all affiliated persons \\
\hline \multirow{3}{*}{$\begin{array}{l}\text { Disclosure } \\
\text { requirements }\end{array}$} & $\begin{array}{c}\text { An obligation for agencies responsible for administering pension schemes to disclose comprehensive and accurate information } \\
\text { regarding scheme assets and liabilities, administrative costs, administration charges, uncollected contributions, and withdrawal } \\
\text { application processing time }\end{array}$ \\
\hline & A statutory right of access to information held by regulatory authorities and agencies responsible for administering pension schemes \\
\hline & Provision for regulatory authorities to access pension scheme records \\
\hline \multirow[t]{2}{*}{$\begin{array}{l}\text { Augment scheme } \\
\text { solvency }\end{array}$} & $\begin{array}{l}\text { Provision to augment pension fund solvency (such as a requirement for the payment of a security bond at initial registration, or a } \\
\text { requirement for the accumulation of reserves) }\end{array}$ \\
\hline & $\begin{array}{l}\text { Provision for the protection of accumulated assets in the event of a scheme being wound up, including industry- and state-sponsored } \\
\text { guarantee funds, a requirement for scheme sponsors to take out indemnity insurance, and state underwriting of pension scheme } \\
\text { liabilities }\end{array}$ \\
\hline \multicolumn{2}{|r|}{ Degree of inclusiveness } \\
\hline Access & Universal coverage for those involved in productive activity \\
\hline \multirow{2}{*}{$\begin{array}{c}\text { Benefit } \\
\text { entitlements }\end{array}$} & Uniform notional contribution rate for those engaged in domestic labour, tied to an index of remuneration for salaried care workers \\
\hline & Entitlements tied to an index of lifetime earnings \\
\hline \multicolumn{2}{|r|}{ Fittingness } \\
\hline $\begin{array}{l}\text { Returns to } \\
\text { financial services }\end{array}$ & Disclosure requirements regarding investment portfolios, rates of return achieved, and rate of return assumptions \\
\hline \multirow{2}{*}{$\begin{array}{l}\text { Returns to } \\
\text { investors }\end{array}$} & Disclosure requirements regarding externalities arising from investment decisions, and associated corporate transactions \\
\hline & Progressive taxation of investment income \\
\hline
\end{tabular}

feminists, appropriate desert bases should be grounded in socially valued activities, defined broadly to encompass the responsibilities that are integral to the reproduction of society. Ginn [18] reminds us that the unpaid work of those who are involved in domestic labour "brings a double contribution to welfare systems: on the one hand, it increases the availability of men for paid work, and on the other, it relieves the state of part of its' obligation to children, the elderly and the sick" (p. 15).

The second group (which may overlap with the first) is comprised of those who are acknowledged by the state to be "economically active", but who are in "atypical" employment. Many existing supplementary retirement schemes exclude from coverage the self-employed, part-time and contract workers, and employees whose earnings fall below a particular income threshold. Again, research suggests that this has impacted disproportionately on women workers, diminishing their capacity to save for retirement [18]. These outcomes are of course inconsistent with economic desert, which requires the allocation of income in accordance with productive achievement.

Clearly, the central issue here is the injustice of the employment based system of resource allocation from which deferred earnings are derived, highlighting the importance of a programme of "transformative redistribution" to ensure that all who are responsible for productive achievements are appropriately remunerated, empowering individuals to make regular contributions to a supplementary retirement scheme. A less favoured but perhaps more immediately feasible alternative for Fraser [34] is to "redress maldistribution by altering end-state patterns of allocation, without disturbing the underlying mechanisms that generate them" (p. 45), encompassing measures to facilitate the inclusion of those who are marginalised by formal employment based systems of resource allocation in the provisions of supplementary pension arrangements. The problem of access to supple- 
mentary retirement schemes could be addressed by mandating universal coverage for those involved in productive activity, regardless of the form that it takes, its sectoral locus, or the number of hours that it involves. The only condition that must be satisfied is the definitional requirement that activity can only be regarded as "productive" if it results in the production of goods and services that have "value to society", either because they are demanded by consumers, or because they contribute towards the "common good", as defined by the public authority [3, 21]. The development of an appropriate benefit formula to cover periods when the affiliated individual is involved in unpaid domestic labour, however, highlights several complex issues.

As we have noted, entitlements under DB schemes typically reflect two considerations. The first is the affiliated individual's record of contributions, which is unproblematic for those who have been continuously employed throughout their working lives. But how should contributions be determined during periods where the affiliated individual is involved in unpaid domestic labour? To the extent that this has been addressed by existing retirement systems, the most prevalent approach is to derive a notional contribution rate from an index of earnings in formal employment, such as the affiliated individual's earnings prior to their involvement in domestic labour [18]. This could be justified in terms of opportunity cost, or the sacrifice involved in giving up the advantages of paid employment, but it is vulnerable to the objection that earnings at earlier points in people's working lives are irrelevant to any appraisal of their current involvement in productive activity. Our conceptualisation of economic desert requires remuneration to be derived primarily from the productive achievements for which individuals are responsible. So when a person ceases their employment, their productive contribution ceases, and with it the claim to earnings [17]. To exempt any particular group from this requirement would be inconsistent with our broad approach, and could result in morally arbitrary transfers, including inequalities in remuneration that are not derived from productive achievement.

In principle, this requires us to determine a notional contribution rate in terms of some index of differentials in the productive achievements that are realised through unpaid domestic labour, and in particular, the production of the next generation of citizens and the routine care of dependent adults. But such an enterprise may be hampered by intractable epistemic difficulties, as White [21] acknowledges. There are, potentially, enormous problems in distinguishing domestic labour that counts only as a private good from work that may properly be regarded as delivering value to society: "depending on what view the community has [if it has one], having and raising children does become, beyond a point, a purely private good" (p. 111). Furthermore, the productive achievements that are realised through domestic labour may not be knowable until a substantial period of time has elapsed (when for example children make the transition to adulthood and become the next generation of citizens). Above all, we might suggest, the domestic sphere is not a place of employment where labour is routinely appraised by supervisors and managers, and any attempt to embrace this model would be regarded as unjustifiably intrusive. But if the productive achievements that are realised through domestic labour cannot be known with any degree of precision, on what basis can they be legitimately remunerated? Miller [3] argues persuasively that where there is uncertainty regarding people's respective desert claims, the appropriate default rule is an equal distribution of resources, since this is likely to minimise the injustice of distributive outcomes. If this is accepted, the fairest approach would be to apply a uniform notional contribution rate to those who cease their employment to undertake unpaid caring responsibilities, linked perhaps to some index of the remuneration of salaried care workers.

The second consideration that typically influences the determination of benefit entitlements under DB schemes is the specific profile of individual earnings to which they should be related at the point of retirement. Existing DB schemes have embraced a range of approaches including lifetime earnings, average earnings during the final years of work, or the average of the best years of earnings. The latter approach is the most advantageous for those who are involved in unpaid domestic labour, and is unlikely to disadvantage those whose employment has been continuous [18]. However, the requirement for remuneration to track individual productive achievements suggests that benefits should be determined in accordance with an index of lifetime earnings, rather than that proportion that yields the most generous entitlements. This should be applied uniformly to affiliated individuals when they reach retirement, since the notion of fair opportunity requires all with appropriate desert bases to be treated in an equivalent way.

The third issue is what has been described elsewhere as the degree of fittingness (Table 2) between appropriate desert bases and the allocation of rewards [8], particularly that proportion of remuneration for productive achievement that is accounted for by retirement income. The desert principle requires the elimination of retirement income transfers that cannot be justified unambiguously in terms of the individual's prior productive achievements, such as entitlements to survivors' benefits, which typically apply regardless of the prior involvement of beneficiaries in caring for dependents [18]. The appropriate basis of treatment in a desert-focussed supplementary pillar is the individual's own productive achievements, not that of other agents.

Concerns regarding fittingness are illustrated poignantly by the growing importance of financial markets to the accumulation of retirement assets. Can the flows of remuneration that this entails be regarded as consistent with the desert based requirement that resource allocation should track individual differences in productive achievement? This is relevant to our concerns in at least two ways. The first concerns the justness of returns to those with the responsibility for managing the investment of retirement assets? Baker and Fung [35] argue vociferously that the financial services industry exploits those whose productive achievements are genuine, by extracting an undeserved surplus from their deferred earnings. However, this line of reasoning ignores the distinctive and important role of the financial services industry in augmenting retirement income. For White [21], returns to the ownership of productive assets may generally be regarded as justifiable in terms of the desert principle to the extent that they are "generative"- that is, they reflect an expansion of production possibilities 
beyond what they would otherwise have been. Thus, returns to those who are responsible for the management of retirement assets may be justified to the extent that their decision making is focused on generating, and achieves, a satisfactory rate of return. But they are unjustified when investment transactions are undertaken solely for the purposes of augmenting commission revenue, highlighting the importance of measures to ensure that capital markets are appropriately regulated.

Similarly, can the interest that is earned on retirement assets be regarded as being consistent with the principle of desert? It could be argued that the value of retirement savings increases over time as a result of factors that have nothing to do with the productive effort of future retirees. White [21] identifies two possible grounds for believing the opposite. The first is where retirement assets have been invested in "a way that expands the community's production possibilities" (p. 121). Note that the emphasis on community implies a model of economic development which benefits all stakeholders. This highlights the importance of statutory measures to monitor and regulate the investment of retirement assets. But even where this has been achieved, it could still be argued that future retirees are not actively involved in generating the outcomes that result from the investment of their contributions. The second possible justification, then, concerns the sacrifice that is involved in deferring immediate consumption. For White [21], this suggests that returns should track the degree of sacrifice, which is arguably greatest for low-income employees, yet "capital markets do not discriminate between savers making genuine sacrifices and those not: in a perfectly competitive market, all get the same rate of interest" (p. 123), which means that some interest income may be unjustified. This could of course be addressed appropriately by maintaining a robust element of progressivity in the tax treatment of interest income.

Liberalism's endorsement of the desert principle as integral to a morally acceptable distribution of retirement income, then, acknowledges that public action is morally justified to ensure that people get only what they deserve from retirement pension systems on the basis of their productive achievement.

\section{CITIZENSHIP}

Miller's third mode of societal relationship is "citizenship", giving rise to the principle of "equality" [3]. The moral force of this element of distributive justice rests on the claim that "members of a political society are related not just through their communities and their instrumental associations but also as fellow citizens...Someone deprived of this equal enjoyment is a second class citizen" (p. 30). Fitzpatrick [36] reminds us that the emphasis of citizenship on the equal status of all members of a community can be "unpacked in very different ways, depending on which set of political ideas we bring to bear" (p. 76). To the extent that they have addressed this issue, liberals maintain that the core rationale of citizenship is equal regard for the liberties of all members of society [19]. Liberty is defined broadly in terms of sovereignty, or the freedom of agents to pursue their own ends, which requires the absence of restrictions on individual action. As Carter [37] explains, justice consists of a "distribution of freedom that is either maximal or in some sense fair-in other words...justice means in part 'maximal freedom' or a 'minimal freedom for all'" (p. 4). The appropriate equalisandum is not material resources per se but the societal distribution of freedom. Social institutions may therefore be regarded as just to the extent that the principle of equal regard for the liberties of all members of society is reflected in their design.

\section{Normative Foundations}

The liberal public philosophies that have informed our analysis embrace radically different approaches to the notion of equality. Libertarians generally define the legitimate scope of equality as the statutory protection of all individuals against coercion [5]. For natural rights libertarians, an appropriate regime of negative rights delimits the range of legitimate possibilities for sovereign action (or "action spaces"), providing all agents with the opportunity to live virtuously [38]. To the extent that it impinges on the separateness of persons, substantive equality is incompatible with individual liberty. In a similar vein, consequentialist libertarians assert that the economic freedom that results from the protection of negative rights maximises competition, separating concerns of economic efficiency from irrelevant individual characteristics, and ensuring that agents are treated according to their merit. Shapiro [4] reminds us that the personality traits of the enterprising individual, including "diligence, reliability and persistence are valued by employers: people with those traits are those more likely to be hired, stay hired, and be promoted, thus increasing their chance of improving their situation" ( $p$. 211), including their retirement trajectories. When employers express preferences regarding the deployment of labour that are not related to productive efficiency, they incur higher costs. This deters unfair discrimination, suggesting that equality of opportunity is an inevitable by-product of a competitive market economy. For libertarians, then, it is a distinctive form of procedural equality that counts for appraising the justness of social institutions: the protection of negative rights for all individuals, which will of course result in substantive inequalities.

Liberal egalitarians generally affirm the importance of negative rights, but do not regard the absence of coercion as a sufficient condition for a maximally free society. Plant [39] insists that the notion of individual capacities must be regarded as integral to any adequate understanding of individual freedom, and for two specific reasons. First, it should inform the conceptualisation of freedom. Negative rights have value precisely because they protect a sphere of action in which agents are able to exercise sovereignty regarding fundamental aspects of their welfare. But if liberty is conceptualised in this way, it becomes "quite difficult to maintain that freedom and ability are totally separable" ( $\mathrm{p}$. 3). An adequate conceptualisation of freedom must take account of the capacity of agents to act in terms of the possibilities that are delimited by their negative rights. Second and reflecting this, individual capacities are a salient criterion for appraising the degree to which agents are able to exercise freedom: "a generalised capacity to do $\mathrm{X}$ is a necessary condition for determining whether $\mathrm{A}$ is able to do $X "$ (p. 4). The possibility of sovereign action is of course 
influenced by a range of contingencies, but our principal concern here is the importance of external resources and opportunities. Individual freedom may be regarded as more extensive where agents are protected from coercion, and where they are able to access the opportunities and resources that are essential to sovereign action. It requires both negative and positive rights.

So what does this imply for public policy? The importance of positive rights is underlined by much of the contemporary literature regarding the material foundations of freedom. Echoing TH Marshall's seminal work on citizenship, Doyal and Gough [40] insist that the case for "positive social rights provides the justification for state responsibility for health, education, income maintenance and a host of other public services" (p. 298). These distinctive resources are relevant to the development of individual capacities for sovereign action in specific ways, but our focus on pensions means that we are necessarily concerned with purchasing power or income. The core rationale of citizenship as equal regard for the liberties of all members of society suggests that one of the principal aims of statutory income transfer programmes should be to maximise individual freedom, by appropriately transferring the resources that are necessary to augment individual autonomy [39].

In sum, the principle of citizenship requires well enforced negative rights to define the boundaries of appropriate action spaces, and social rights to guarantee the resources that enable agents to take full advantage of their liberties.

\section{Programme Design}

Which particular attributes of pension scheme design are necessary to protect the basic liberties of all? Carter [37] highlights the foundational importance of two forms of liberty. The first is freedom that has "constitutive value", where the actions that are permitted form "a constitutive part of some intrinsically valuable thing" (p. 54). The cessation of employment on the grounds of retirement (Table 3 ) is constituted in part by individual choice regarding participation in economic activity.

While the notion that retirement is "intrinsically" valuable may be contentious, there are several reasons why liberals might regard it as a legitimate element of the good life. Most fundamentally, liberal freedom requires social institutions to be designed so as to enable agents to pursue their sovereign preferences which means, inter alia, that employment or any other form of economic activity should not be regarded as compulsory. In "developed" countries, where retirement is a stable societal expectation, a life that concludes with a period where individuals are permanently exempted from economic activity is widely regarded as a good life. Crucially, the material preconditions for the freedom to disengage from economic activity are acknowledged to the extent that the "normal" retirement age (NRA) is linked to eligibility for statutory income transfers [20]. Older people in "developing" countries, in contrast, are generally not entitled to statutory income transfers on the grounds of retirement. The absence of such protection means that they are forced to work until they can no longer work, suggesting that retirement is not widely regarded as an integral element of the good life. But where it is so regarded, the liberal emphasis on the importance of equal regard for the basic liberties of all means that the entitlements that are encompassed by the NRA should be universal.

In practice, there are several ways in which retirement policy may be incompatible with the requirements of this moral imperative. Perhaps the most obvious is where differentials in the NRA are permitted and justified in terms of moral criteria that are irrelevant to citizenship. Is it fair for example that the NRA in western societies is typically lower for women, in spite of their greater average life expectancy? This has been justified in at least two ways. One argument asserts that women are typically expected to shoulder the "double burden" of domestic labour and low paid employment, and have thus "earned" an earlier retirement [41]. Similarly, Schokkaert and Van Parijs [19] highlight the argument that the prevalence of gender differentials in the distribution of retirement income easily earns women "the modest privilege of enjoying their pensions for a longer time" (p. 257). For both arguments, the preferential treatment of women is regarded as just compensation for their economic and social disadvantages.

Although these are important arguments, their relevance to citizenship is questionable. As we have suggested, entitlements that arise from appropriate desert bases should properly be regarded as the concern of the contributory second pillar pension arrangement. But our focus at this point is the universal entitlements that give adequate expression to the principle of equal regard for the basic liberties of all, and not the differential entitlements that arise from desert claims. Is there anything about the particular circumstances of women which suggests that their autonomy can only be equivalent to that of men if they are permitted to take an earlier retirement? If the answer is negative, the gendered differentials in the NRA that are prevalent in western societies cannot be justified in terms of citizenship per se. Indeed, when this is considered in terms of the "temporal" autonomy that is permitted by retirement, the reversal of these differentials appears to acquire a greater moral force, as highlighted by Schokkaert and Van Parijs [19]: "as long as men can expect to live less long, or less long in reasonably good health, would it not be fair to allow them to retire earlier than women?" (p. 257). At the very least, the principle of equal regard for the basic liberties of all requires a uniform NRA.

A second way that retirement policy may undermine the capacity of agents to disengage from economic activity concerns the entitlements to statutory income transfers that are tied to the NRA. In a variety of ways, a reliance on social assistance may be incompatible with the basic liberties of the least advantaged. Reflecting a lack of popular support, means tested benefits are likely to be parsimonious, deterring those who have the "choice" from ceasing their employment [15]. Indeed, it is widely acknowledged that the maintenance of incentives to engage with economic activity is the primary rationale of social assistance programmes, as expressed in their core rationale, "less eligibility", which Novak [42] defines as "the principle that relief by the state should always be less attractive than independent wage labour" (p. 46). Where individuals are prevented by retirement law or illhealth from sustaining their economic activity, their 
diminutive benefit entitlements are likely to translate into income deprivation, which may detract from the notion that retirement is an integral element of the good life.

The administration of social assistance may also give rise to differentials in entitlements that impact adversely on the liberties of particular segments of the least advantaged. Where the unit of entitlement is the family, benefits are typically paid to the male "head" of household, reinforcing women's economic dependence on their partner, and reducing their financial autonomy as retirees [18]. For many women, the formal right to retirement is contradicted by the expectation that they will continue to shoulder the responsibility for domestic labour. Novak [42] contends that such discrimination has reflected the centrality of patriarchal assumptions regarding the role and status of women in the household: the proper role of women "is as wives and mothers rather than workers; and...the economic status of women should be that of dependent upon men". Their maintenance should "be provided either through their husband's wage or through his benefit" (p. 153). Although these assumptions are increasingly at variance with the growing prevalence of women's labour force participation, they continue to inform the administration of social assistance programmes. The principle of equal regard for the basic liberties of all thus adds weight to the case for a universal citizens pension: its coverage means that benefit entitlements are unlikely to be parsimonious, augmenting the capacity of agents to cease their work; and the appropriate unit of entitlement is the individual, which means that all are given a degree of financial independence.

It is clear, therefore, that the principle of equal regard for the basic liberties of all requires specific universal entitlements with regard to retirement. Yet such entitlements become problematic when they give rise to, or are associated with, the obligation to cease economic activity. Recall that the broad end of liberal freedom is sovereignty, where individuals are able to pursue their conception of the good life, which may include work participation (Table $\mathbf{3}$ ). This is reinforced by comparative cross-national survey evidence which suggests that a substantial minority of employees would prefer to continue working beyond the NRA [43]. But their capacity to do so may be substantially impaired by retirement policy, and in at least three ways.

The most obvious is mandatory retirement, where individuals are legally obligated to cease their economic activity at a specified age. In practice, social security and employment law across a range of national jurisdictions have converged, giving employers the right to retire their employees when they reach the NRA [43]. The conspicuous exception is the United States which, since 1986, has effectively prohibited mandatory retirement. At the very least, the principle of equal regard for the basic liberties of all requires the generalisation of this approach to all national jurisdictions where retirement is regarded as an integral element of the good life. The NRA should represent an entitlement to cease economic activity at a defined age, where this is desired, not an obligation to withdraw from work.

Even where retirement is not compulsory, the capacity of individuals to participate in economic activity may be impaired by the prejudicial attitudes of employers. Sargeant [43] defines age discrimination as "the rejection of an older worker because of assumptions about the effect of age on the worker's ability to perform, regardless of whether there was any factual basis for the assumption" (p. 5). There is considerable evidence to suggest that the negative attitudes that give rise to age discrimination are widespread. One survey of senior executives in 500 companies sought to gauge the prevalence of prejudice against older workers by asking respondents to specify the age at which they would dismiss a job applicant as being "too old" to employ: more than one third regarded applicants aged 50 and over as being unsuitable for employment, while around two thirds expressed a reluctance to employ applicants who has reached the age of 60 [43].

These attitudes manifest as age discrimination in a variety of ways, including the mis-use of early retirement provisions to dismiss older workers from their employment.

Table 3. The Design Requirements of a Citizenship-Focussed Retirement System

\begin{tabular}{|c|c|}
\hline Design Priorities & Design Features that Augment Justice \\
\hline \multicolumn{2}{|c|}{ Retirement } \\
\hline Retirement age & Uniform NRA \\
\hline Pillar 1 access & Universal transfers for those at NRA and above \\
\hline Pillar 1 unit of entitlement & Individual \\
\hline Pillar 1 benefit adequacy & Appropriate benefit indexation \\
\hline \multicolumn{2}{|c|}{ Work Participation } \\
\hline Retirement age & Voluntary retirement \\
\hline Opportunity to work & Anti-discrimination legislation \\
\hline First pillar income transfer scheme & Universal citizens pension, as above \\
\hline Supplementary retirement scheme & No retirement condition \\
\hline \multirow{2}{*}{ Sovereignty } & Protection of negative rights \\
\hline & $\mathrm{UCP}$ that is as generous as is sustainable \\
\hline
\end{tabular}


Although early retirement is legally "voluntary", corporate restructuring often gives rise to the creation of pressures for older workers to disengage from their employment before they reach the NRA, prompting serious questions regarding the degree to which the decision to take early retirement is an expression of sovereign preferences. Where justice requires institutions to enable agents to pursue their own conception of the good life, including participation in economic activity, these pressures must be regarded as morally unacceptable. A genuine concern with the basic liberties of all requires institutional neutrality regarding competing conceptions of the good life, highlighting the importance of antidiscrimination legislation.

If we assume again that retirement is "voluntary", the capacity of agents to participate in economic activity may be further impaired by the disincentive effects of particular approaches to retirement-income-protection. This impacts on different groups of older people in distinctive ways, depending on the purpose and design of income transfer programmes. Where social assistance benefits are parsimonious, the least advantaged may be discouraged from ceasing their economic activity, as we have acknowledged. But where it is sufficiently "generous", social assistance may deter the least advantaged from seeking and maintaining work, because eligibility requires the absence of alternative sources of income, which means that benefits are withdrawn as earnings from employment rise. This is highlighted by Fitzpatrick [36], who regards the "unemployment trap" as a "consequence of wage levels which are close enough to benefit levels to not make it worthwhile for someone to stop claiming benefits" (p. 57), even if he or she would prefer to. This reinforces the moral case for a universal citizens pension which, because it is unconditional, confers entitlements irrespective of other income.

Turning to supplementary pensions, it is evident that the eligibility conditions that are embedded in the design of some employer-sponsored occupational retirement schemes may inhibit participation in economic activity. A disincentive to remain economically active beyond the pensionable retirement age (PRA) (and by extension, the NRA) can be an effect of abatement provisions, which reduce pension income where the affiliated individual continues to work for the same employer, or in the same occupation [20], making eligibility for supplementary pension benefits dependent on the cessation of employment. According to one United Kingdom survey [43], a substantial proportion of those affiliated to retirement schemes that apply abatement provisions restrict their hours of work or withdraw from work entirely when they reach the PRA, suggesting that the impact of a "retirement condition" in circumscribing participation in economic activity is enormous. A genuine regard for the basic liberties of all means that no particular group of employees should be arbitrarily deterred from working, if this reflects their sovereign preferences.

Carter's second foundational liberty [37] manifests in terms of freedom that has "instrumental value", where the actions that are permitted are necessary to the attainment of other ends. Freedom of choice "isn't pursued for its own sake, but as a precondition for pursuing those projects and tasks that are valued for their own sake" (p. 44). For convenience, we address this in terms of the "non-specific" well-being of retirees, encompassing the (as yet) unidentified purposes that they will pursue across the entire span of their retirement. Since agents cannot know their future needs and preferences with any degree of certainty, the scope of individual freedom must be as broad as possible to permit appropriate action as and when circumstances dictate. The question is, how and to what extent should we regard the distribution of material resources as being relevant to individual sovereignty (Table 3 ) during old age?

As we have noted, libertarians regard the scope of individual sovereignty as being a direct corollary of the absence of coercion, defined specifically as action by agents that violates negative rights. Where there is appropriate protection against coercion, the notion that outcomes may in any meaningful sense be regarded as "sub-optimal" is absurd, for they reflect the individual's capacity to originate value, to be a "setter of ends". The distribution of material resources is relevant to sovereignty only to the extent that it is regarded as a legitimate consequence of voluntary exchange, however unequal. Where negative rights are appropriately protected, the scope of individual sovereignty is as broad as it can be.

The importance of libertarian self-ownership to older people could of course be highlighted by several concerns: the removal of arbitrary statutory restrictions on employment might give them the flexibility to engage with economic activity in the future, if they wish to do so; the protection of property rights might augment their capacity to save, increasing the likelihood of financial security across time; while the abolition of statutory prohibitions on freedom of association could enhance the range of possibilities to engage in meaningful roles and social activities. Yet the libertarian analysis is flawed to the extent that it equates voluntariness of choice with consent, since agents may "agree" to participate in transactions that are fundamentally involuntary. Olsaretti [8] insists that only when everyone is given a "sufficient range of acceptable options can we say that individuals can live their lives in accordance with their voluntary choices, enjoy a robust rather than formal selfownership, and claim that individuals may justifiably be held responsible for the outcomes of their actions" (p. 165). The market fails to guarantee an acceptable range of options for all, including many of those who have reached the NRA.

Liberal egalitarians attach considerable importance to the notion of sovereignty, reflecting the foundational assumption that agents are ultimately responsible for the consequences of their actions, and by extension, the success or failure of their lives. The key role for the public authority, as far as justice is concerned, is to design social and political institutions so that the circumstances of individuals, including those that manifest over the course of their retirement, are a direct corollary of the sovereign decisions that they have made. While this requires statutory protection against coercion, freedom is meaningful to the extent that agents are able to access the external objects that make sovereign decision making and action possible. For Van Parijs [7], "one is really free, as opposed to just formally free, to the extent that one possesses the means, not just the right, to do whatever one might want to do" (p. 33). Thus the resources that retirees have at their disposal represent an 
appropriate indicator of the degree of their overall freedom. The exchange value of resources may indicate not only their utility, but the actions that they make possible for those who possess them. To simplify matters, financial resources may be thought of as an appropriate metric of freedom, since they represent a license to perform actions. This means, as Carter [37] explains, that "any gift of money (including welfare benefits) increases the available set of sets of compossible actions, and any confiscation of money (including taxation) reduces it" (p. 235). A genuine concern with the basic liberties of all retirees requires, in some measure, an egalitarian distribution of retirement income, such as might be achieved by a universal tax-financed income transfer programme [7]. Individual sovereignty during old age requires both formal freedom and autonomy, suggesting that the protection of non-specific instrumental freedom (as well as specific freedoms) requires a combination of negative and positive rights.

\section{CONCLUSION}

So how should we appraise the capacity of pension institutions to achieve distributive justice? For much of the relevant literature, the principal end of justice is social solidarity, defined specifically in terms of the capacity of the working class to initiate, sustain and enjoy the benefits of collective action $[1,2]$. This is exemplified by social democratic retirement systems, where income is allocated substantially in accordance with egalitarian principles. "Liberal" retirement systems are, we are told, incompatible with solidarity, for they allocate income according to differentials in labour force participation, which intensifies social inequality. In short, we should appraise the capacity of retirement systems to achieve distributive justice in terms of the degree to which their design has embraced decommodification.

Although enormously influential, this understanding is inherently flawed by its one-dimensional characterisation of the normative foundations of liberal retirement systems. "Liberal" is equivalent to "neoliberal", which means that liberalism must be regarded as hostile to the decommodifying impetus of social democracy. Yet this fails to acknowledge the variety of ways in which contemporary liberalism has embraced egalitarian concerns. Its emphasis on the centrality of need is inextricably tied to an endorsement of vertical income redistribution to ensure that the least advantaged are able to enjoy a satisfactory standard of living [3]. Its distinctive articulation of the desert principle means that inequalities in the distribution of retirement income can only be regarded as acceptable where everyone has been given the opportunity to develop and deploy their work-relevant talents and abilities [25]. And its acceptance of citizenship manifests as the principle of equal regard for the basic liberties of all [19]. The capacity of retirement systems to achieve distributive justice should be assessed in terms of the degree to which their design has embraced these egalitarian imperatives.

However, there are several issues that require further consideration before applying these justice principles and their corresponding benchmarks in the context of crossnational comparative research. First, what is the relative importance of each of the principles? Our analysis has highlighted the difficulty of achieving consensus-between diverse normative positions, between social security scholars - on the significance of the specific concerns that inform the principles. Nonetheless, a degree of resolution to this perplexing problem is necessary to inform the weighting of the principles, and indeed their corresponding pension scheme design attributes. Second, how do each of the benchmarks translate into a comprehensive range of relevant pension scheme design attributes? Although our discussion of this issue has been necessarily brief, the broader programme of research that has informed our analysis has developed an extensive array of design features that may be used to operationalise principles of justice in the context of institutional design [20]. Finally, there are important methodological issues regarding the conversion of national statutes and associated programme documentation into nationally comparable data regarding the design of pension institutions. The alternative is to rely on existing comparative datasets which, taken together, are characterised by variation in social security terminology, and uneven coverage of private and public pension arrangements. The task of addressing these issues represents an exciting challenge for future social security research.

\section{ACKNOWLEDGEMENTS}

The authors acknowledge the Social Sciences and Humanities Research Council of Canada (SSHRCC) for a grant to finance the research on which this article is based.

\section{REFERENCES}

[1] Esping-Andersen G. The Three Worlds of Welfare Capitalism. Cambridge, England: Polity Press 1990.

[2] Leonard P. Personality and Ideology: Towards a Materialist Understanding of the Individual. Basingstoke, England: Macmillan 1984.

[3] Miller D. Principles of Social Justice. Cambridge, MT: Stanford University Press 1999.

[4] Shapiro D. Is the Welfare State Justified? Cambridge, England: Cambridge University Press 2007.

[5] Kelly D. A Life of One's Own: Individual Rights and the Welfare State. Washington, DC: The Cato Institute 1998.

[6] Dworkin R. Sovereign Virtue: The Theory and Practice of Equality. Cambridge, MA: Harvard University Press 2000.

[7] Van Parijs P. Real Freedom for All: What (if anything) can justify capitalism? Oxford, England: Oxford University Press 1995.

[8] Olsaretti S. Liberty, Desert and the Market: A Philosophical Study. Cambridge, England: Cambridge University Press 2004.

[9] Möllering G. Understanding Trust from the Perspective of Sociological Neoinstitutionalism. Cologne: Max Planck Institut für Gessellschaftforschung 2005.

[10] Miller D. What is Social Justice? In: Pearce N, Paxton W, Eds. Social Justice: Building a Fairer Britain, London, England: Politicos 2005; pp. 3-20.

[11] Mitchell O, Utkus S, Eds. Pension Design and Structure: New Lessons From Behavioral Finance. Oxford, England: Oxford University Press 2004.

[12] Rawls J. A Theory of Justice. Cambridge, MA: Harvard University Press 1971 .

[13] Barry N. Welfare. Buckingham, England: Open University Press 1999.

[14] Reisman D. Richard Titmuss: Welfare and Society. Basingstoke, England: Macmillan 1977.

[15] Alcock P. Socialist security: where we should be going and why. Crit Soc Pol 1985; 5: 217-33.

[16] Hills J. Inclusion or Insurance? National Insurance and the future of the contributory principle. London, England: London School of Economics 2003. 
[17] Goodin RE. Stabilizing expectations: the role of earnings-related benefits in social welfare policy. Ethics 1990; 100: 530-53.

[18] Ginn J. Actuarial fairness or social justice? A gender perspective on redistribution in pension systems. Turin, Italy: Center for Research on Pensions and Welfare Policies 2004.

[19] Schokkaert E, Van Parijs P. Social justice and the reform of europe's pension systems. J Eur Soc Pol 2003; 13 (3): 245-79.

[20] Hyde M, Dixon J, Drover G. The Privatisation of Mandatory Retirement Income Protection: International Perspectives. Lewiston, NY: Edwin Mellen Press 2006.

[21] White S. The Civic Minimum. Oxford, England: Oxford University Press 2004.

[22] Meyer T, Bridgen, P, Reidmüller B, Eds. Private Pensions versus Social Inclusion? Non-State Provision for Citizens at Risk in Europe. Cheltenham, England: Edward Elgar 2007.

[23] Willmore L. Universal Pensions for Developing Countries. Laxenburg, Austria: International Institute for Applied Systems Analysis 2006.

[24] World Bank. Averting the Old Age Crisis: Policies to Protect the Old and Promote Growth. Washington, DC: The World Bank 1994.

[25] Olsaretti S, Ed. Desert and Justice. Oxford, England: Clarendon Press 2007.

[26] Schmidtz D, Goodin RE. Social Welfare and Individual Responsibility. Cambridge, England: Cambridge University Press 1998.

[27] McLeod O. Desert. In: Zalta E, Ed. Stanford Encyclopaedia of Philosophy, Stanford, CA: Stanford University Press 2003; pp. 118.

[28] Freeden M. Rights. Buckingham, England: Open University Press 1991.

[29] Kangas O. The Grasshopper and the Ants: Popular Opinions of Just Distribution in Australia and Finland. Sidney, Australia: Social Policy Research Centre, University of New South Wales 2007.
[30] Vail J. States of insecurity: the political foundations of insecurity. In: Vail J, Wheelock J, Hill M, Eds. Insecure Times, London, England: Routledge 1999; pp. 41-57.

[31] Hill M. Pensions. Bristol, England: Policy Press 2007.

[32] Rounds CE. Property Rights: The Hidden Issue of Social Security Reform. In: Tanner D, Ed. Social Security and Its Discontents, Washington, DC: The Cato Institute 2004; pp. 69-80.

[33] Schmidtz D. Elements of Justice. Cambridge, England: Cambridge University Press 2006.

[34] Fraser N. Social Justice in the Age of Identity Politics: Redistribution, Recognition and Participation. Salt Lake City, UT: Tanner Humanities Center 1996.

[35] Baker D, Fung A. Collateral Damage: Do Pension Fund Investments Hurt Workers? In: Fung A, Hebb T, Rogers J, Eds. Working Capital: The Power of Labour's Pensions, London, England: Ithaca 2001; pp. 13-43.

[36] Fitzpatrick T. Freedom and Security: An Introduction to the Basic Income Debate. Basingstoke, England: Palgrave 1999.

[37] Carter I. A Measure of Freedom. Oxford, England: Oxford University Press 1999.

[38] Macey JR. On the failure of Libertarianism to Capture the Popular Imagination. In: Frankel Paul E, Miller F, Paul J, Eds. Problems of Market Liberalism, Cambridge, England: Cambridge University Press 2003; pp. 372-411.

[39] Plant R. Can there be a right to a basic income? Louvain-la-Neuve, Belgium: Basic Income Earth Network 2002.

[40] Doyal L, Gough I. A Theory of Human Need. Basingstoke, England: Macmillan 1990

[41] Gillion C, Turner J, Bailey C, Latulippe D. Social Security Pensions: Development and Reform. Geneva: International Labour Office 2000.

[42] Novak T. Poverty and the State. Buckingham, England: Open University Press 1988

[43] Sargeant M. Mandatory retirement age and age discrimination. Emp Rel 2004; 26 (2): 151-66.

(C) Hyde et al.; Licensee Bentham Open

This is an open access article licensed under the terms of the Creative Commons Attribution Non-Commercial License (http: //creativecommons.org/licenses/by$\mathrm{nc} / 3.0 /$ ), which permits unrestricted, non-commercial use, distribution and reproduction in any medium, provided the work is properly cited. 